\title{
Comparative study of control of hyperglycemia and dyslipidemia between two treatment- groups of diabetic patient (Metformin Monotherapy and Metformin + Glimepiride Combination)
}

\author{
Subhradipta Bhattacharyya ${ }^{1 *}$, Brijesh Mukherjee ${ }^{2}$ \\ ${ }^{1}$ Demonstrator, ${ }^{\mathbf{2}}$ Associate Professor, ${ }^{\mathbf{1}}$ Dept. of Pharmacology, ${ }^{2}$ Dept. of Biochemistry, ${ }^{\mathbf{1}}$ NRS Medical College \& Hospital, Kolkata, West \\ Bengal, ${ }^{2} \mathrm{Hi}$-tech Medical College and Hospital, Rourkela, Odisha, India
}

\begin{abstract}
Aim: The aim of the study is to examine whether the combination of metformin+ glimepiride is superior to metformin mono therapy to treat the newly diagnosed type $2 \mathrm{DM}$ patients to control the HbA1C and dyslipidaemia in terms of LDL, total cholesterol, TG etc.

Materials and Methods: A Prospective randomised study with four groups. The control comprises of 60 healthy volunteers. 120 newly diagnosed type 2 DM cases (Group 1) were enrolled in the study. These 120 patients were randomised into two groups; Group 2 with 60 patients to receive Metformin and Group 3 with 60 patients to receive Metformin + glimepiride combination. Both the Group 2 and Group 3 have received the same hypolipidemic and antihypertensive drugs.

Results: After about 4 years of treatment, in Group 2 and Group 3, FPG, HbA1C\% and lipid profile were improved significantly (p<0.05) than the values before treatment started. Group 3 patients (metformin + glimepiride) had slightly better glycaemic control $(\mathrm{P}=0.85)$ than Group 2 patients (metformin only). Group 3 patients had also better control over Cholesterol and LDL level, LDL-C/HDL-C, TC/HDL-C than Group B patients.

Conclusion: Metformin and Glimepiride combination therapy improves HbA1c, LDL-C, HDL-C more effectively. However, Group 2 patients had shown better AIP than Group 3 patients.
\end{abstract}

Keywords: Monotherapy, Combination therapy, Glycaemic control, Dyslipidemia, Atherogenesis.

\section{Introduction}

Type $2 \mathrm{DM}$ is the most common form of diabetes occurring in the adult population. Metformin is one of the primary drugs to be prescribed to the newly diagnosed patients as monotherapy along with diet and life style modification. ${ }^{1}$ When metformin alone is not sufficient to control hyperglycemia with optimum dose, Sulfonylureas or DPP-4 inhibitors are added. Sometimes monotherapy with sulfonylurea or DPP-4 inhibitors are started in newly diagnosed patients. The combined regimens ${ }^{2}$ like metformin + Sulfonylurea or metformin + DPP-4 inhibitors etc. are started when adequate glycemic control is not achieved with a single agent. Dyslipidemia ${ }^{3}$ with premature atherosclerotic cardiovascular disease is a dreadful complication to be seen in patients suffering from type 2 DM. Patients are prescribed antilipidemic drugs like statin, fibrates etc. along with oral hypoglycemics \pm insulin. OHA like metformin lowers the plasma LDL or TG modestly itself ${ }^{4}$ Again, metformin lowers plasma lipid and glucose synergistically with statins ${ }^{5}$ specially those patients who respond well to metformin therapy measured by $>1 \%$ reduction of $\mathrm{HbAlc}$ after 3 months. ${ }^{6}$ In this prospective clinical study, it was tried to evaluate whether metformin + glimepiride combination therapy is superior over metformin monotherapy $^{7,8}$ to lower HbA1c and lipid profile. The parameters like BMI, FPG, HbAlc, cholesterol, LDL-C, HDL-C, VLDL-C, TG, LDL-C/HDL-C ratio, TC/HDL-C ratio, AIP $(\log \text { TG/HDL-C })^{9,10}$ etc. were measured at frequent interval in each groups and analysed to compare the efficacy between monotherapy and combination therapy.

\section{Materials and Methods}

It is an open label randomised prospective study. At first 120 newly diagnosed type 2 DM patients were included in the study. For comparison of clinical and laboratory parameters healthy volunteers were enrolled and designated as CONTROL.

The Control Group comprises of 60 healthy volunteers with mean age of $40.15 \pm 8.18$ (SD) years. The age of 120 newly diagnosed type 2 DM cases i.e GROUP 1, was $53.65 \pm 4.45$ (SD) years. These 120 patients were randomised into two equal groups; Group 2 with 60 patients to receive Metformin only and Group 3 with 60 patients to receive Metformin + glimepiride combination.

Group 2 (average age 54.29 \pm 3.47 years) patients were periodically evaluated over mean $2.81 \pm 0.92$ years of treatment with Metformin and anti lipidemic drug. Group 3 consists of 60 patients also with average 53.7 \pm 2.69 (SD) years of age were treated with Metformin+ Glimepiride for average $3.12 \pm 1.06$ years and evaluated at regular basis. Both the Group 2 and Group 3 have received the same hypolipidemic drug and antihypertensive drugs. Blood parameters like HbA1C (primary endpoint) ${ }^{11}$, FPG, LDL, total cholesterol, TG etc. (secondary endpoint) were

\footnotetext{
*Corresponding Author: Subhradipta Bhattacharyya, Dept. of Pharmacology, ${ }^{1}$ NRS Medical College \& Hospital, Kolkata, West Bengal, India

Email: subhradiptabhattacharyya@gYahoo.co.in

http://doi.org/ 10.18231/j.ijcaap.2019.019
} 
periodically evaluated along with $\mathrm{BP}, \mathrm{BMI}, \mathrm{ECG}$, renal function etc. ${ }^{12,13}$

\section{Statistical Evaluation}

The continuous data were represented in mean \pm SD. The comparison between two mean was analysed by using student's t-test. ANOVA test was applied to analyse the difference between more than two means. ${ }^{14,15} \mathrm{P}$ value $<0.05$ was considered to be statistically significant. EXCEL software was used for statistical analysis.

\section{Results}

The healthy volunteers had expectedly much better clinical profile and blood parameters than Group 2 and Group 3 patients. Mean BMI of the control group measured to be $23.16 \pm 2.87 \mathrm{Kg} / \mathrm{M}^{2}$. Mean BMI of the newly diagnosed type 2 diabetes cases $27.15 \pm 3.66 \mathrm{Kg} / \mathrm{M}^{2}$.

Group 2 who are on treatment with metformin have mean BMI $25.98 \pm 3.37 \mathrm{Kg} / \mathrm{M}^{2}$ with mean duration of treatment of $4.11 \pm 1.12$ years.

Group 3 who are treated with mean duration of $4.17 \pm 1.10$ years with both metformin and glimepiride found to have mean BMI of $26.38 \pm 3.89 \mathrm{Kg} / \mathrm{M}^{2}$. FPG of the control group was measured to be $84.06 \pm 7.02 \mathrm{mg} / \mathrm{dl}$. In the newly diagnosed cases(Group 1) FPG were found to be $216 \pm 41.4$ $\mathrm{mg} / \mathrm{dL}$ which was improved both in Group 2 and Group 3 with the mean FPG $125.28 \pm 23.4 \mathrm{mg} / \mathrm{dl}$ and $138.6 \pm 22.84$ $\mathrm{mg} / \mathrm{dl}$ respectively.

Control group has within normal\% $\mathrm{HbA}_{1} \mathrm{C}$ i.e mean $4.35 \pm 0.63$. In newly diagnosed cases initial mean $\% \mathrm{HbA}_{1} \mathrm{C}$ was $9.39 \pm 1.24$. Expectedly, the mean $\% \mathrm{HbA}_{1} \mathrm{C}$ of Group 2 (on Metformin only) was reduced to $7.40 \pm 1.84$ whereas in Group 3 (to receive both Metformin and Glimepiride) it dropped down to mean $\% \mathrm{HbA}_{1} \mathrm{C}$ of $7.09 \pm 1.02$.

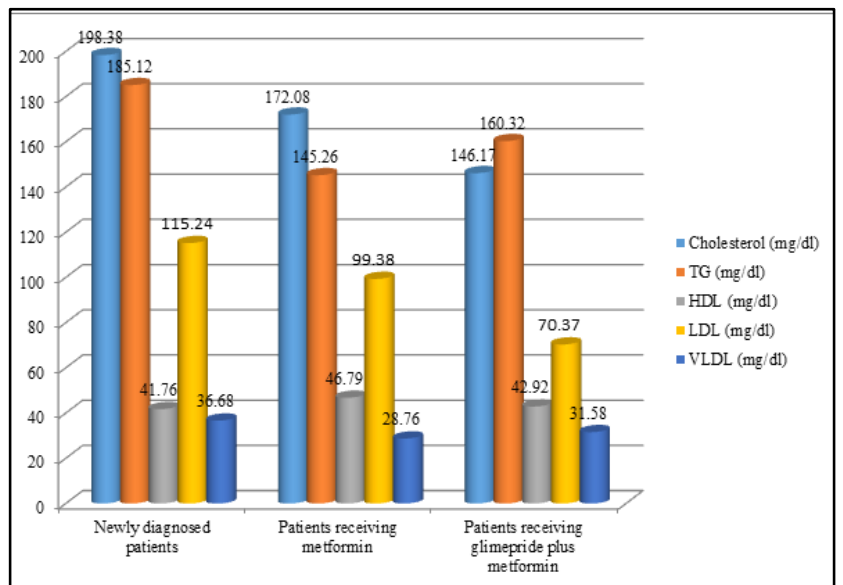

Fig. 1: LIPID profile of newly diagnosed type $2 \mathrm{dm}$ patients before \& after treatment with comparison between monotherapy \& combined therapy

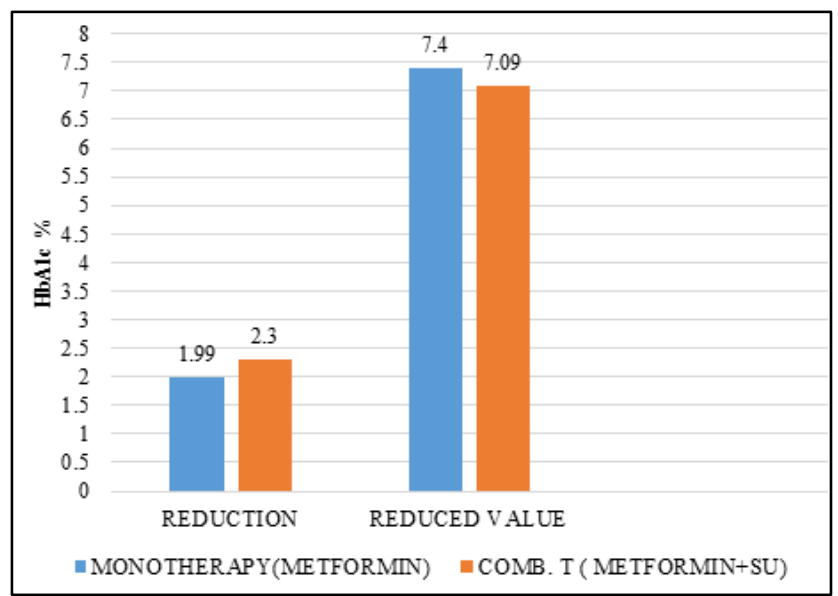

Fig. 2: Comparison of reduction of hbalc values with monotherapy \& combination therapy

\section{LIPID Profile}

The cholesterol of different groups were measured, that of Control was $156.99 \pm 34.42 \mathrm{mg} / \mathrm{dl}$. (mean \pm SD). Before treatment in newly diagnosed cases, the mean cholesterol was $198.38 \pm 44.47 \mathrm{mg} / \mathrm{dl}$, after 4 years treatment with dyslipidemic drugs, mean cholesterol in Group 2 was reduced to $172.08 \pm 55.68 \mathrm{mg} / \mathrm{dl}$ and in Group 3 it was reduced to $146.17 \pm 49.88 \mathrm{mg} / \mathrm{dl}$ respectively. Greater reduction of plasma cholesterol was noted in Group 3 patients.(Gr 3: $52.21 \mathrm{mg} / \mathrm{dl}$ vs Gr 2: $26.3 \mathrm{mg} / \mathrm{dl})$. As earlier mentioned, both the groups were treated with same dyslipidemic drug.

The patients to receive combination therapy had shown better improvement in LDL profile than their peers to receive only metformin. In newly diagnosed patients before the treatment (Group 1) the mean LDL was measured to be $115.24 \pm 34.42 \mathrm{mg} / \mathrm{dL}$. In the Group 2 patients with metformin therapy the mean LDL was reduced to $99.38 \pm 47.18 \mathrm{mg} / \mathrm{dL}$ and for Group 3 patients there was much greater improvement to be $70.37 \pm 49.11 \mathrm{mg} / \mathrm{dL}$. The mean LDL of the control was found to be $69.61 \pm 18.17$ $\mathrm{mg} / \mathrm{dL}$.

However, greater reduction of initial plasma values of HDL, VLDL and triglyceride are observed in monotherapy group than combination treatment group which is not commensurated with the findings of LDL or Total cholesterols. In the untreated patients i.e Group 1, at their diagnosis mean triglyceride was $185.12 \pm 85.92 \mathrm{mg} / \mathrm{dl}$. In group 2 after 4 years of treatment the TG was reduced to $145.26 \pm 62.89 \mathrm{mg} / \mathrm{dl}$ and group 3 to have $160.32 \pm 51.37$ $\mathrm{mg} / \mathrm{dl}$ respectively. The mean triglycerides of Control group was found to be $120.46 \pm 39.86 \mathrm{mg} / \mathrm{dl}$. 


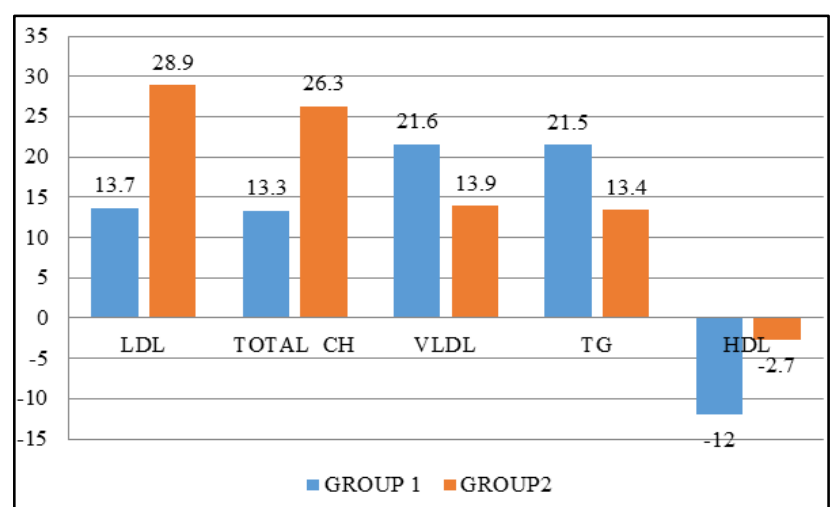

Fig. 3: Comparative changes of lipid profile between mono (group 1) \& combination treatment (group 2).

The mean HDL of control group was measured to be $54.14 \pm 11.99 \mathrm{mg} / \mathrm{dL}$. In newly diagnosed group i.e. Group 1 , the mean HDL was found to be $41.76 \pm 6.19 \mathrm{mg} / \mathrm{dL}$. In Group 2 patients treated with Metformin only the mean HDL was measured to be $46.79 \pm 7.35 \mathrm{mg} / \mathrm{dL}$. Mean HDL was found to be $42.92 \pm 6.57 \mathrm{mg} / \mathrm{dL}$ in case of Group 3 patients who were treated with metformin $+\mathrm{SU}$ combination.

The mean VLDL was measured to be $23.86 \pm 3.47$ $\mathrm{mg} / \mathrm{dL}$ in control groups. The mean VLDL values were measured to be $36.68 \pm 7.34 \mathrm{mg} / \mathrm{dL}$ for Group 1 , $28.76 \pm 5.41 \mathrm{mg} / \mathrm{dL}$ for Group 2 and $31.58 \pm 4.63 \mathrm{mg} / \mathrm{dL}$ for Group 3 respectively.

Other atherogenic lipid profile like LDL-C/ HDL-C, TC/HDL-C were better controlled with combination therapy. From same baseline value of 2.75, LDL-C/HDL-C was reduced to 2.1 in monotherapy, whereas in combination therapy the ratio was reduced to 1.63 . TC/HDL-C was reduced from same baseline value 4.7 , to 3.7 in monotherapy and 3.4 in combination therapy respectively. However, AIP (Atherogenic index of Plasma) was reduced more in monotherapy (0.49), than combination therapy (0.57) from the same base line value of 0.64 .

\section{Discussion}

$\mathrm{HbA1c}$ has been taken as the primary endpoint of hypoglycemic efficacy. Reduction of glycated haemoglobin is proportional to the reduction of CVS risk and other macrovascular as well as microvascular complications. ${ }^{16,17}$ As described before, $2.3 \%$ reduction of $\mathrm{HbA1C}$ (statistically significant $p<0.001$ ) was observed in Group 3 patients with combination therapy from initial value of $9.39 \pm 1.24$. In monotherapy i.e Group 2 patients $1.99 \%$ reduction was observed from initial value of $9.39 \pm 1.24$. (also statistically significant $\mathrm{p}<0.001)$. However, the difference between two reductions with monotherapy and combination therapy is not statistically significant $(\mathrm{p}=0.85)$ i.e it can not be said that superiority of combination therapy to reduce $\mathrm{HbA1C}$ is statistically significant than monotherapy.

In our study, statin was used as primary dyslipidemic drug. However, metformin lowers specially LDL-C and total cholesterol apart from synergistic action with statin to improve hyperglycemia and dyslipidemia. Metformin lowers lipid profile by i. increasing insulin sensitivity, therefore reduces lipolysis and lipoprotein precursors to TG/VLDL synthesis in liver, ii. Improving hyperglycemia reduces irreversible glycation of LDL and hastens removal from body iii. inducing weight loss augments dyslipidemia correction. ${ }^{18}$

Along with greater reduction of $\mathrm{HbAlc}$, greater reduction of LDL-C, cholesterol, LDL/HDL etc. were observed in two treatment groups. Since both the groups were having same dyslipidemic drugs, there is obvious positive corelation between glycemic control (HbA1c level) and dyslipidaemia correction. ${ }^{19,20}$ Hyperglycaemia induces glycation of lipoproteins, particularly low-density lipoproteins (LDL), preventing the recognition of apoprotein $\mathrm{B}$ by the specific receptor leading to reduced clearance from plasma and favouring the accumulation of LDL in macrophages and their oxidation leading to atherosclerosis ${ }^{21}$ Therefore, correction of chronic hyperglycemia with reduced biomarker $\mathrm{HbAlc}$, also reduces lipoprotein glycation, leads to efficient removal from plasma and normalisation of LDL level.

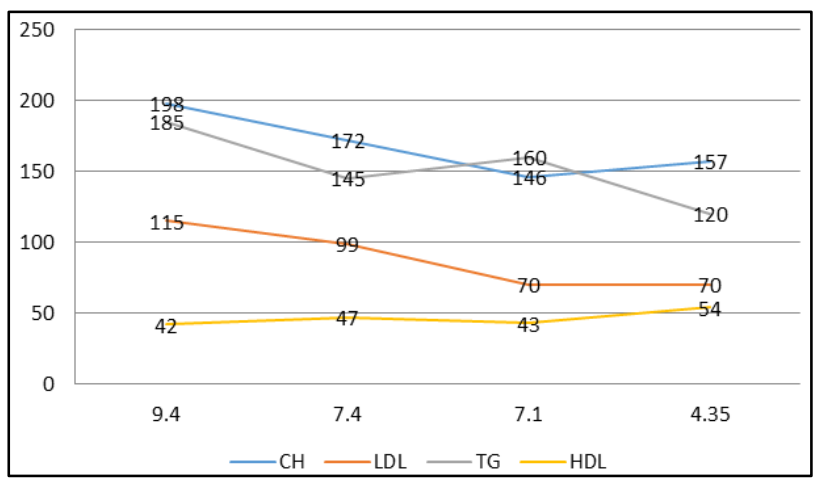

Fig. 4: Relation of reduction in lipid profile with $\mathrm{HbA} 1 \mathrm{c} \%$

LDL-C and TC reduction were proportionate to reduction of glycosylated $\mathrm{Hb} \%$. [in combination therapy, $24.5 \%$ reduction of $\mathrm{HbA} 1 \mathrm{c} \%$ and in monotherapy $21.2 \%$ reduction.] Reduction of LDL value in case of monotherapy was $15.86 \mathrm{mg} / \mathrm{dl}$ and in case of combination therapy the reduction is $44.87 \mathrm{mg} / \mathrm{dl}$. The difference in reduction of LDL between two groups of patients by is statistically significant ( $\mathrm{p}$ value $<0.001)$. 
Table 1: comparative changes $(\Delta)$ of different parameters between Monotherapy and Combination therapy group after 3 years of treatment

\begin{tabular}{|c|c|c|c|c|c|}
\hline Parameter & $\begin{array}{c}\text { Monotherapy } \\
\text { (group 2) }\end{array}$ & \% & $\begin{array}{c}\text { Combination } \\
\text { Therapy (group 3) }\end{array}$ & \% & P value \\
\hline$\Delta$ HbA1C & -1.99 & -21.2 & -2.3 & -24.5 & 0.85 \\
\hline$\Delta$ LDL & -15.86 & -13.7 & -44.87 & -38.9 & $<0.001$ \\
\hline$\Delta$ TG & -39.86 & -21.5 & -24.8 & -13.4 & $>0.1$ \\
\hline$\Delta$ CHOLESTEROL & -26.3 & -13.3 & -52.21 & -26.3 & $<0.01$ \\
\hline$\Delta$ VLDL & -7.92 & -21.6 & -5.1 & -13.9 & $<0.01$ \\
\hline$\Delta$ HDL & +5.03 & +12 & +1.16 & +2.7 & $<0.01$ \\
\hline
\end{tabular}

In case of Cholesterol, the reduction was $26.3 \mathrm{mg} / \mathrm{dl}$ in monotherapy whereas it is $52.21 \mathrm{mg} / \mathrm{dl}$ in case of combination therapy. The difference in reduction between two groups is statistically significant ( $\mathrm{p}$ value $<0.001$ ).

However in case of TG and VLDL, in case of monotherapy greater reduction was observed than the combination therapy. VLDL was reduced by $7.92 \mathrm{mg} / \mathrm{dl}$ in case of monotherapy whereas it was reduced by $5.1 \mathrm{mg} / \mathrm{dl}$ in combination therapy and the difference in reduction is statistically significant ( $\mathrm{p}$ value $<0.01$ ). TG was reduced by $39.86 \mathrm{mg} / \mathrm{dl}$ in case of monotherapy whereas it was reduced by $24.8 \mathrm{mg} / \mathrm{dl}$ in combination therapy and the difference of reduction was not significant ( $\mathrm{p}$ value $>0.01$ ).

There was greater increase in HDL value observed in case of monotherapy $(5.03 \mathrm{mg} / \mathrm{dl})$ than the combination therapy $(1.16 \mathrm{mg} / \mathrm{dl})$ and the difference in increase is statistically significant $(\mathrm{p}$ value $<0.01)$.

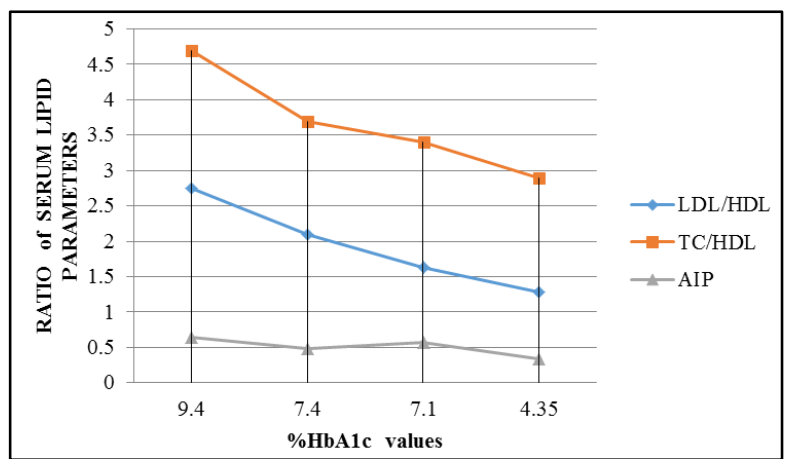

Fig. 5: Relation of LDL/HDL, TC/HDL and AIP with $\mathrm{HbA1c}$

Normal Value: $\mathrm{LDL} / \mathrm{HDL}=1-1.5 \mathrm{TC} / \mathrm{HDL}=2.5-3.5$ $\mathrm{TG} / \mathrm{HDL}=$

AIP (Atherogenic Index of Plasma $)=$ LOG $($ TG/HDL $)=0.2$ $-0.5$

\section{Mixed response in glycemic and lipid profile due to glimepiride}

On Glimepiride addition, mixed favourable outcome in lipid and glycemic profile was observed.

The group 3 patients treated with both metformin and glimepiride had better glycemic (HbA1c) control (though FPG is worse) and TC, LDL-C control. However the TG, VLDL and HDL, AIP (greater AIP in glimepiride+ group) profile was worse than the group 2 patients. One of the possible reason for elevated TG and VLDL in Group 3 patients due to increased TG synthesis in liver due to intake of Sulfonylurea (Glimepiride). Since the patients were newly diagnosed DM 2, they have $\beta$ cell reserve. On receiving glimepiride, there was increased insulin concentration in plasma. ${ }^{22}$ The glucose control was satisfactory but the hypertriglyceridemia was prevailed by increased plasma insulin level in circulation due to induction of the enzyme AcylcoA carboxylase ${ }^{23}$ and Fatty acid synthase enzyme complex in hepatocytes and intestine. $^{24}$ Besides, depressed lipoprotein lipase in circulation can not remove TG but in adipose tissue uninhibited hormone sensitive lipase (due to insulin resistance) degrades ester to release more free fatty acids supply to liver for TG synthesis. ${ }^{25}$ Again increased free fatty acid worsened the insulin resistance state, consequently increased CETP action transfers TG in exchange of cholesterol to LDL and HDL. These newly formed TG rich LDL and HDL lipoproteins are better substrate to hepatic lipase action to produce small dense atherogenic LDL \& HDL particles. ${ }^{26}$

The newly diagnosed DM type 2 patients remain in a state of insulin resistance. Insulin resistance is started either before or along with onset of reduction of beta cell mass during the pathogenesis. However, there is no grown resistance against Insulin action observed to the triglyceride and VLDL synthesis. ${ }^{25}$ The relatively increased level of VLDL, TG and AIP are observed along with FPG level than the monotherapy group. The increased insulin resistance observed in Group 3 patients probably due to adverse CVS effect of glimepiride. ${ }^{27,28}$ Thus increased CVS risk with more atherogenic lipid profile with sulfonylurea use $\mathrm{e}^{29}$ has been observed in this study.

\section{Conclusion}

Those patients who received two drugs had better HbA1c reduction (though statistically not significant) than monotherapy. The two drug regimen was not superior over monotherapy to reduce $\mathrm{HbA} 1 \mathrm{c} \%$ and both the regimens were highly efficacious to reduce hyperglycemia. LDL-C, TC, LDL/HDL and TC/HDL were better corrected $(\mathrm{p}<0.01)$ in combination therapy than metformin only group. These reductions of LDL and total cholesterol were proportional to HbA1c reductions. Those patients to receive SU showed relatively elevated parameters like AIP, FPG, VLDL, TG suggestive of worsened insulin resistance and increased atherogenecity presumably due to adverse CVS effects of sulfonylurea. 


\author{
Abbreviation used \\ AIP = Atherogenic index of plasma. \\ CETP $=$ Cholesterol ester transfer protein .
}

\section{Conflict of Interest}

None.

\section{Source of Funding}

None.

\section{References}

1. Nasri H, Rafieian-Kopaei M. Metformin: current knowledge, $J$ Res Med Sci 2014;19(7):658-64. Review. PMID:25364368

2. Moon MK, Hur K, Ko S, Park S, Lee B, Combination Therapy. Combination Therapy of Oral Hypoglycemic Agents in Patients with Type 2 Diabetes Mellitus. Diabetes Metab J 2017;41:357-66

3. Schofield JD. Liu Y. Balakrishna PR. Rayaz A. Malik. Handrean Soran. Diabetes Dyslipidemia. Diabetes Ther 2016;7:203-219.

4. Lin SH, Cheng PC, Tu ST, Hsu SR, Cheng YC, Liu YH, Pleotropic Effect of Metformin on Lipid. Effect of metformin monotherapy on serum lipid profile in statin-naïve individuals with newly diagnosed type 2 diabetes mellitus: a cohort study Peer J 6:e4578; DOI 10.7717/peerj.4578.

5. Metformin on lipid Mariël F. van Stee, Albert A. de Graaf and Albert K. Groen.Actions of metformin and statins on lipid and glucose metabolism and possible benefit of combination therapy. Cardiovasc Diabetol 2018;17:94

6. Kashi Z, Mahrooz Ak, Kianmehr A, Alizadeh A. HbA1C. Metformin Response The Role of Metformin Response in Lipid Metabolism in Patients with Recent-Onset Type 2 Diabetes: HbA1c Level as a Criterion for Designating Patients as Responders or Nonresponders to Metformin. Plos One | DOI:10.1371/journal.pone.0151543 March 15, 2016.

7. Maruthur NM, Tseng E, Hutfless S, Wilson LM, Metformin Comb Therapy. Diabetes Medications as Monotherapy or Metformin-Based Combination Therapy for Type 2 Diabetes. Ann Intern Med 2016;164(11).

8. Sulfonylurea Vs Hemmingsen MB, Schroll JB, Wetterslev J, Sulfonylurea versus metformin monotherapy in patients with type 2 diabetes: a Cochrane systematic review and metaanalysis of randomized clinical trials and trial sequential analysis CMAJ Open 2014.DOI:10.9778/cmajo.20130073.

9. (Michel P Hermans, Sylvie A Ahn and Michel F Rousseau The atherogenic dyslipidemia ratio $[\log (\mathrm{TG}) / \mathrm{HDL}-\mathrm{C}]$ is associated with residual vascular risk, beta-cell function loss and microangiopathy in type 2 diabetes females. Lipids in Health and Disease 2012;11:132.

10. Ray S, Talukdar A, Sonthalia N, Saha M, Kundu S, Serum lipoprotein ratios as markers of insulin resistance:A study among non-diabetic acute coronary syndrome patients with impaired fasting glucose. Indian J Med Res 2015;141; 62-7.

11. Irene M Stratton, Amanda I Adler, H Andrew W Neil, David R Matthews, Susan E Manley, Carole A Cull. Association of glycaemia with macrovascular and microvascular complications of type 2 diabetes (UKPDS 35): prospective observational study. BMJ 32112 AUGUST 2000 bmj.com 405.

12. Aclan Ozder. Lipid profile abnormalities seen in T2DM patients in primary healthcare in Turkey: a cross-sectional study. Lipids in Health Dis 2014;13:183.
13. Jorge 1. Gross, md mirela j. De azevedo, md sandra p. Silveiro, md lu' is henrique canani, md maria luiza caramori, md themis zelmanovitz, md. Diabetic Nephropathy: Diagnosis, Prevention, and Treatment. Diabetes Care 2005;28:176 -188.

14. B K Mahajan. Biostatistics. $7^{\text {th }}$ edition.

15. Bernard Rosner. Fundamentals of Biostatistics. $7^{\text {th }}$ edition.

16. Hb a1c and CVS Risk. Elizabeth Selvin, MPH; Spyridon Marinopoulos, Gail Berkenblit, Meta-Analysis: Glycosylated Hemoglobin and Cardiovascular Disease in Diabetes Mellitus. Ann Intern Med. 2004:141:421-31.

17. Mette V Skriver, Annelli Sandbæk, Jette K Kristensen, Henrik Støvring. Relationship of HbA1c variability, absolute changes in $\mathrm{HbA1c}$, and all-cause mortality in type 2 diabetes: A Danish population-based prospective observational study. BMJ Open Diabetes Res Care 2015;2:e00060. doi:10.1136/bmjdrc-2014000060.

18. Lin SH, Cheng PC, Tu ST, Hsu SR, Cheng YC, Liu YH et al. Effect of metformin monotherapy on serum lipid profile in statin-naïve individuals with newly diagnosed type 2 diabetes mellitus: a cohort study. Peer J 6:e4578; DOI 10.7717/peerj.4578.

19. Magri CJ, Mintoff D, Camilleri L, Xuereb RG, Galea J, Fava S et al. Relationship of Hyperglycaemia, Hypoglycaemia, and Glucose Variability to Atherosclerotic Disease in Type 2 Diabetes. J Diabetes Res 2018, Article ID 7464320, 9 page.

20. Hussain A, Ali I, Ijaz M, Rahim A. Correlation between hemoglobin A1c and serum lipid profile in Afghani patients with type 2 diabetes: hemoglobin A1c prognosticates dyslipidemia. Ther Adv Endocrinol Metab 8(4)Received: 3 November 2016; accepted in revised form: 13 January 2017.

21. Lipoprotein glycation and oxidation..Picard S, Lipoprotein glyco-oxidation. Diabete Metab 1995;21(2):89-94.

22. MOA SU Daniele Sola1, Luca Rossi1, Gian Piero Carnevale Schianca2, Pamela Maffioli3, Sulfonylureas and their use in clinical practice. Arch Med Sci 2015;11;4:840-8.

23. HARPER

24. Mariël F. van Stee, Albert A. de Graaf1 and Albert K. Groen, Actions of metformin and statins on lipid and glucose metabolism and possible benefit of combination therapy. Cardiovasc Diabetol 2018;17:94 https://doi.org/10.1186/s12933-018-0738-4

25. Harrison. Metabolic syndrome, chapter 422 \& PART 16

26. Blood lipid abnormalities, chapter 18 , Rudy Bilous MD, FRCP. Richard Donnelly MD, PHD, FRCP, FRACP. Handbook of Diabetes, 4th edition, John Wiley \& Sons, Ltd., Publication.

27. SU \& CVS RISK. David S.H. Bell. Do sulfonylurea drugs increase the risk of cardiac events? CMAJ 2006;174(2).

28. Higher Dose and CVS Risk, SU.. Scot H. Simpson, Sumit R. Majumdar, Ross T. Tsuyuki Dose-response relation between sulfonylurea drugs and mortality in type 2 diabetes mellitus: a population-based cohort study. CMAJ 2006;174(2):169-74.

29. Roumie CL, Hung AM, Greevy RA, Grijalva CG, Metformin Su Cvs Risk. Comparative effectiveness of sulfonylurea and metformin monotherapy on risk of cardiovascular events in type 2 diabetes mellitus. Ann Intern Med 2012;157(9):601-10. doi:10.7326/0003-4819-157-9-201211060-00003.

How to cite this article: Bhattacharyya $S$, Mukherjee $B$. Comparative study of control of hyperglycemia and dyslipidemia between two treatment- groups of diabetic patient (Metformin Monotherapy and Metformin + Glimepiride Combination). Int $J$ Comprehensive $A d v$ Pharmacol 2019;4(3):91-5. 